Review Article

\title{
Oxidative Stress-Related Endothelial Damage in Vascular Depression and Vascular Cognitive Impairment: Beneficial Effects of Aerobic Physical Exercise
}

\author{
Maria Luca $(\mathbb{D})$ and Antonina Luca $(1 D)$ \\ Department of Medical, Surgical Sciences and Advanced Technologies “GF Ingrassia”, University of Catania, Italy \\ Correspondence should be addressed to Antonina Luca; antolucaster@gmail.com
}

Received 26 October 2019; Accepted 11 December 2019; Published 20 December 2019

Academic Editor: Valentina Pallottini

Copyright (C) 2019 Maria Luca and Antonina Luca. This is an open access article distributed under the Creative Commons Attribution License, which permits unrestricted use, distribution, and reproduction in any medium, provided the original work is properly cited.

\begin{abstract}
Oxidative stress- (OS-) related endothelial damage is involved in the occurrence and progression of several disorders, such as vascular depression and dementia. It has been reported that moderate, aerobic, physical exercise could reduce OS and inflammation, thus limiting the cardiovascular risk factors while improving endothelial homeostasis, mood, and cognition. In this review, we will discuss about the role of OS and OS-related endothelial damage in vascular depression and vascular cognitive impairment. Then, we will comment on the effects of physical exercise on both disorders.
\end{abstract}

\section{Oxidative Stress, Endothelium, and Physical Exercise}

During physical exercise, the production of reactive oxygen species (ROS), including hydroxyl radical $(\mathrm{OH}-)$, hydrogen peroxide $\left(\mathrm{H}_{2} \mathrm{O}_{2}\right)$, and superoxide $\left(\mathrm{O}_{2}-\right)$, increases. The fine balance between ROS and antioxidants, namely, redox homeostasis, is involved in various physiological processes including cellular signaling, gene expression, cellular growth, neurotransmitter release, and synaptic plasticity $[1,2]$. Hence, a ROS overproduction can lead to detrimental effects for the cells. In fact, containing unpaired electrons, ROS are highly reactive molecules that can oxidize several cellular compounds, among which DNA, lipids, and proteins [3]. The main endogenous sources of ROS are probably the mitochondria, followed by peroxisomes and endoplasmic reticulum, while exogenous ROS-inducing agents are pollutants, xenobiotics, bacteria, radiations, diet, excessive physical exercise, etc. [4]. The imbalance between ROS generation and antioxidant substances determines oxidative stress (OS), condition favoring the occurrence and progression of several chronic illnesses such as dementia, movement disorders, depression, and cardiovascular disturbances [5-7]. In addition, ROS overproduction induces an inflammatory status, characterized by a release of cytokines, prostaglandins, and chemokines whose pivotal role in the occurrence of the previously mentioned disorders has been fully elucidated [8]. Among the conditions accompanied by sustained OS, overtraining has been demonstrated to determine an excessive production of ROS, thus favoring DNA damage, lipid peroxidation, and necrosis [9]. Conversely, moderate aerobic physical exercise leads to a transient elevated ROS production, an increased muscle contractility, an improvement of insulin sensibility, and a better regulation of vasodilatation [10]. Furthermore, moderate physical exercise improves the endogenous antioxidant defense system, stimulating the expression of superoxide dismutase 1, superoxide dismutase 2, glutathione peroxidase, and glutathione reductase, while reducing the concentration of several inflammatory markers, including interleukin- (IL-) 6, homocysteine, and tumor necrosis factor-alpha [11]. From a clinical point of view, the beneficial effects of moderate physical exercise result in a lower incidence of ischemic stroke, heart attacks [12], obesity, and diabetes [11] among trained individuals. Exercise seems to exert 
its beneficial role both directly, improving the insulin sensitivity and the mobilization of fatty acids and glucose, and indirectly, by favoring weight loss [13]. Moreover, a recent animal study has demonstrated that exercise increases the endothelial nitric oxide synthase (eNOS) expression and activation both in the vascular wall and in the perivascular adipose tissue, thus restoring their anticontractile capacity with the consequent improvement of the vascular function [14]. The latter mechanism could explain, at least in part, the beneficial role of exercise training on several acute and chronic disorders related to vascular dysfunction, including vascular cognitive impairment (VCI) and vascular depression $(\mathrm{VaD})$. In this review, we will discuss about the role of OS and OS-related endothelial damage in VCI and VaD. Then, we will comment on the effects of physical exercise on both disorders.

\section{The Role of Vascular Endothelium in Depression}

2.1. Vascular Depression. Depression is one of the most frequent mental disorders (lifetime prevalence of 20.6\%) that, according to the World Health Organization projections, could become the leading cause of disability by $2030[15,16]$.

The most frequent depressive symptoms are sad mood, thoughts of guilt, lack of interest, sleep disorders, lack of appetite, psychomotor retardation or agitation, cognitive deficits, and suicidal ideation $[17,18]$. Among the different neurobiological mechanisms contributing to the occurrence of depression, it is possible to include the serotoninergic, norepinephrinergic, and dopaminergic deficits, the dysfunction of the hypothalamic-pituitary-adrenal (HPA) axis, the hyperproduction of proinflammatory mediators, and an altered gut-brain axis [19]. Despite the median age at depression onset typically being the early adulthood [20], depressive symptoms are common in the elderly and are associated with reduced quality of life and elevated mortality [21]. Over the years, several factors have been variably associated with the occurrence of late-life depression, including social isolation, poor family support, low education, marital status [22], Parkinson's disease, diabetes, cancer, and cerebrovascular disorders [22-24]. The association between cerebrovascular disorders and depression in late-life has been so frequently reported that the concept of "vascular depression," subtype of late-life depression frequently predisposed or perpetuated by an ischemic damage of frontosubcortical circuits, emerged [25]. As a matter of fact, a recent meta-analysis supported the association between brain silent lesions due to vascular damage (white matter lesions (WMLs)) and late-life depression [26]. WMLs are commonly observed in the elderly; they are frequently related to structural and functional cerebrovascular pathology and are facilitated by the endothelial dysfunction [27-29].

2.2. Vascular Endothelium and Vascular Depression. Vascular endothelium is a single cellular layer that lines the walls of all blood vessels. Releasing both vasodilators (i.e., nitric oxide) and vasoconstrictors (i.e., endothelin), it regulates the vasomotor tone, thus exerting a fundamental role in the prevention of cerebrocardiovascular disorders [30]. Endothelial dysfunction could contribute to the occurrence of $\mathrm{VaD}$, as discussed below.

Firstly, an association between risk factors for endothelial damage (i.e., hyperglycemia, hypertension, and dyslipidemia) and depression has been reported [31, 32]. Moreover, homocysteine, a toxic amino acid derived from dietary methionine and representing a strong risk factor for cerebrocardiovascular disorders (due to vasodilatation impairment), has been found to be elevated in depressed patients [33]. Interestingly, depression is frequently characterized by functional alterations affecting crucial components of the bloodbrain barrier (BBB), such as a reduced E-cadherin expression (resulting in less efficient tight junctions) and an impaired function of claudin, a protein contributing to the formation and maintenance of the $\mathrm{BBB}$. These functional changes are favored by the prooxidative and proinflammatory status [34]. In fact, OS seems to directly upregulate the endothelial expression of NMDA receptor in the neurovascular unit, thus mediating endothelial excitotoxicity [35]. Another OSrelated condition characterizing depression is the activation of metalloproteinases 2 and 9, proteins demonstrated to increase the BBB permeability and stimulate the inflammatory status $[34,36,37]$. A dysregulated function of metalloproteinases, altering the neurovascular unit, favors neuronal damage and cognitive impairment. Consistently, high levels of metalloproteinase 9 have been detected in the vascular walls, senile plaques, and neurons of brains affected by Alzheimer's disease (AD) [38]. Interestingly, physical exercise has been repeatedly shown to reduce the levels of metalloproteinases $[39,40]$ and to improve the endothelial function, also through its stimulatory effect on eNOS [41, 42].

The since here discussed molecular alterations could account, at least in part, for the frequent association between depression and neurological conditions (i.e., traumatic brain injury, stroke, and multiple sclerosis) characterized by endothelial dysfunction and inflammation [34]. Concerning the latter, depression is characterized by the release of inflammatory molecules inducing vascular damage, such as IL-6- and cytokine-like leptin, an anorexogenic agent linked to the eating disturbances frequently associated with late-life depression [43-45]. In the latter type of depression, the endothelial damage is further stimulated by the age-related dysfunctional hyperactivation of glial cells, determining the release of several proinflammatory cytokines and ROS hyperproduction [46, 47]. Finally, the autonomic dysfunction characterizing mood disorders may as well sustain endothelial dysfunction $[48,49]$. For example, an imbalance between sympathetic and parasympathetic tone, common in the elderly, has been related to myocardial infarction and ischemic stroke [30]. As a matter of fact, the relationship between vascular damage and depression seems to be "bidirectional": if, on the one hand, endothelial damage could sustain depression, on the other hand, depression itself represents a cerebrocardiovascular risk factor. As a result, elderly depressed patients frequently show an impairment in activities of daily living as well as cognitive decline and increased medical comorbidity [50]. 


\section{Vascular Cognitive Impairment and Endothelium}

The term vascular dementia, recently substituted by the more inclusive term "vascular cognitive impairment" (VCI), encompasses a range of cognitive disorders strictly related to vascular disease [51]. Despite the large variability in the esteems, VCI is still considered the second most common type of dementia, after $\mathrm{AD}$, accounting for $15-20 \%$ of individuals affected by dementia [52]. Epidemiological studies reported that cerebrovascular disorders increase from 3.5 to 47 times the risk of dementia, depending on the severity of the vascular event (i.e., silent WMLs, transient ischemic attacks, minor stroke, and stroke) [53]. The differences in the epidemiological data can be reconducted in the variety in terms of frequency, features, and prognosis characterizing the disorders classified under the umbrella term "VCI." It should be noted, in fact, that the many faces of VCI reflect the heterogeneous nature of the vascular damage and its distinct contribution to the occurrence of cognitive decline. Hence, among VCI disorders, it is possible to include multi-infarct (cortical vascular) dementia, small vessel (subcortical vascular) dementia, strategic infarct dementia, hypoperfusion dementia, hemorrhagic dementia, hereditary vascular dementia (including the cerebral autosomal dominant arteriopathy with subcortical infarcts and leukoencephalopathy CADASIL), and $\mathrm{AD}$ with cerebrovascular disease (cooccurrence of neurodegeneration and vascular damage) [54]. Cerebral small vessel disease is the most common form of brain vascular disorder [55] and is held responsible not only for vascular dementia but also for vascular parkinsonism, sometimes difficult to distinguish from idiopathic Parkinson's disease and atypical parkinsonism [56, 57].

Vascular brain pathology is anything but rare in the elderly and could cause cognitive deficit ranging from mild cognitive impairment to dementia [58]. From a clinical point of view, $\mathrm{VCI}$ is characterized by extremely variable cognitive deficits, highly dependent on vascular damage localization and severity, as previously stated. However, due to the frequency of small vessel disease, clinical manifestations related to the frontostriatal circuit impairment, including executive function and attention deficits, are usually observed [59]. The most studied risk factors variably associated with VCI are represented by old age, low educational level, smoking status, hypertension, diabetes, obesity, and hypercholesterolemia [60]. These factors, some of them modifiable, cooccur in a scenario of age-related modifications exerting a detrimental effect on the endothelium. In fact, from a molecular point of view, aging is characterized by an imbalance between oxidants and antioxidants. The consequent ROS overproduction in the vascular system, including brain circulation, could be partially related to the overexpression of NADPH oxidases, characterizing the elderly [61]. In addition, OS determines the hyperactivation of glycogen synthase kinase (GSK-3) and, consequently, an alteration of mitochondrial permeability, recognized to exert a pivotal role in the pathogenesis of atherosclerosis [62, 63]. Moreover, aging is characterized by microglial hyperactivation. This condition represents a defensive response to inflammation; however, particularly when sustained, it constitutes a dangerous source of free radicals, ultimately favoring OS and neurodegeneration [50]. The latter could be further facilitated by the aging-related impairment of the brain autoregulation myogenic tone and the $\mathrm{BBB}$ breakdown, leading to the passage of immune cells and toxins into the brain $[64,65]$. On the light of what has been said, the interplay between inflammation and OS could represent the biological basis of endothelial damage and $\mathrm{BBB}$ break failure occurring in $\mathrm{VaD}[66,67]$.

\section{Physical Exercise in Vascular Depression and Vascular Cognitive Impairment}

The pharmacological treatment of depression and dementia in the elderly is frequently complicated by poor compliance, drug side effects, and interactions due to multiple therapies. Therefore, nonpharmacological approaches, as monotherapy or in add-on to pharmacological agents, are receiving increasing interest.

Physical exercise exerts beneficial effects in terms of psychological well-being, quality of life, and depressive symptoms [68]. In fact, it has been demonstrated to be as effective as the antidepressant sertraline and to reduce depressive symptoms in nonresponders to antidepressants $[69,70]$. Notably, a relatively recent meta-analysis confirmed the benefit of exercise on depression, even in comparison with active usual care (i.e., social contact) [71]. Since vascular dysfunctions are shared by both late-life depression and VCI [72], VaD could be more than a risk factor for VCI. In fact, a continuum from late-life depression to VCI could be hypothesized. In this context, physical exercise may represent a viable strategy to prevent cognitive impairment in the elderly. In fact, studies carried out on middle-aged individuals with normal cognition identified moderate cardiorespiratory fitness as a protective factor against cognitive impairment, being able to improve attention and executive function performances $[73,74]$. These findings could find an explanation in some molecular mechanisms highlighted in humans and animal models of AD. For instance, physical exercise seems to improve the clearance of $\mathrm{A} \beta$ plaques and hyperphosphorylated tau protein [75]. On the other hand, physical exercise limits OS, favoring an increase of the peripheral insulin-like growth factor 1, stimulating the activity of superoxide dismutase and decreasing the NADH oxidase activity [76]. A further mechanism supporting the beneficial role of physical exercise in VCI is represented by the stimulation of the neurogenesis in the subventricular and subgranular zone and an increased angiogenesis of capillaries from existing vessels [76]. Interestingly, randomized controlled trials have confirmed that physical exercise may delay the cognitive decline characterizing $\mathrm{AD}$ [77] and $\mathrm{VCI}$ $[78,79]$. Unfortunately, despite the recommendations of the World Health Organization and the encouraging evidence, physical inactivity is still a major concern when considering middle-aged individuals [80]. Future studies are needed in order to strengthen the current evidence regarding the role of physical exercise in both $\mathrm{VaD}$ and $\mathrm{VCI}$ and raise awareness on this issue. 


\section{Conclusion}

The previously discussed evidence highlights the beneficial effects of moderate, aerobic, physical exercise in reducing the cerebrocardiovascular risk factors, as well as improving endothelial homeostasis, mood, and cognition. Hence, the elderly should be encouraged to maintain an active lifestyle to reduce the risk of disabilities in late-life.

\section{Conflicts of Interest}

The authors declare that there is no conflict of interests regarding the publication of this paper.

\section{Authors' Contributions}

Maria Luca and Antonina Luca contributed equally to this work.

\section{References}

[1] Y. S. Bae, H. Oh, S. G. Rhee, and Y. D. Yoo, "Regulation of reactive oxygen species generation in cell signaling," Molecules and Cells, vol. 32, no. 6, pp. 491-509, 2011.

[2] W. Dröge, "Free radicals in the physiological control of cell function," Physiological Reviews, vol. 82, no. 1, pp. 47-95, 2002.

[3] C. A. Massaad and E. Klann, "Reactive oxygen species in the regulation of synaptic plasticity and memory," Antioxidants \& Redox Signaling, vol. 14, no. 10, pp. 2013-2054, 2011.

[4] D. I. Brown and K. K. Griendling, "Nox proteins in signal transduction," Free Radical Biology \& Medicine, vol. 47, no. 9, pp. 1239-1253, 2009.

[5] P. L. Chiang, H. L. Chen, C. H. Lu et al., "Interaction of systemic oxidative stress and mesial temporal network degeneration in Parkinson's disease with and without cognitive impairment," Journal of Neuroinflammation, vol. 15, no. 1, 2018.

[6] C. N. Black, M. Bot, P. G. Scheffer, P. Cuijpers, and B. W. J. H. Penninx, "Is depression associated with increased oxidative stress? A systematic review and meta-analysis," Psychoneuroendocrinology, vol. 51, no. 1, pp. 164-175, 2015.

[7] A. Gudjoncik, C. Guenancia, M. Zeller, Y. Cottin, C. Vergely, and L. Rochette, "Iron, oxidative stress, and redox signaling in the cardiovascular system," Molecular Nutrition \& Food Research, vol. 58, no. 8, pp. 1721-1738, 2014.

[8] M. T. Islam, "Oxidative stress and mitochondrial dysfunctionlinked neurodegenerative disorders," Neurological Research, vol. 39, no. 1, pp. 73-82, 2017.

[9] C. Nocella, V. Cammisotto, F. Pigozzi et al., "Impairment between oxidant and antioxidant systems: short- and longterm implications for athletes' health," Nutrients, vol. 11, no. 6, p. 1353, 2019.

[10] M. Ristow, K. Zarse, A. Oberbach et al., "Antioxidants prevent health-promoting effects of physical exercise in humans," Proceedings of the National Academy of Sciences of the United States of America, vol. 106, no. 21, pp. 8665-8670, 2009.

[11] E. Koloverou, K. Tambalis, D. B. Panagiotakos et al., "Moderate physical activity reduces 10-year diabetes incidence: the mediating role of oxidative stress biomarkers," International Journal of Public Health, vol. 63, no. 2, pp. 297-305, 2018.
[12] M. Wei, L. W. Gibbons, J. B. Kampert, M. Z. Nichaman, and S. N. Blair, "Low cardiorespiratory fitness and physical inactivity as predictors of mortality in men with type 2 diabetes," Annals of Internal Medicine, vol. 132, no. 8, pp. 605-611, 2011.

[13] Y. S. Kim, J. S. Nam, D. W. Yeo, K. R. Kim, S. H. Suh, and C. W. Ahn, "The effects of aerobic exercise training on serum osteocalcin, adipocytokines and insulin resistance on obese young males," Clinical Endocrinology, vol. 82, no. 5, pp. 686694, 2015.

[14] C. Meziat, D. Boulghobra, E. Strock et al., "Exercise training restores eNOS activation in the perivascular adipose tissue of obese rats: impact on vascular function," Nitric Oxide, vol. 86, pp. 63-67, 2019.

[15] World Health Organization The global burden of disease2004 update. 2004. Retrieved from: http://www.who.int/entity/ healthinfo/global_burden_disease/GBD_report_2004update_ full.pdf.

[16] D. S. Hasin, A. L. Sarvet, J. L. Meyers et al., "Epidemiology of adult DSM-5 major depressive disorder and its specifiers in the United States," JAMA Psychiatry, vol. 75, no. 4, pp. 336346,2018

[17] M. Luca, A. Luca, and C. Calandra, "Psychomotor retardation and externally oriented thinking in major depression," Neuropsychiatric Disease and Treatment, vol. 9, pp. 759-766, 2013.

[18] American Psychiatric Association, Diagnostic and Statistical Manual of Mental Disorders, American Psychiatric Association, Arlington, VA, USA, Fifth Edition (DSM-5) edition, 2013.

[19] M. Luca, M. di Mauro, M. di Mauro, and A. Luca, "Gut microbiota in Alzheimer's disease, depression, and type 2 diabetes mellitus: the role of oxidative stress," Oxidative Medicine and Cellular Longevity, vol. 2019, Article ID 4730539, 10 pages, 2019.

[20] R. C. Kessler and E. J. Bromet, "The epidemiology of depression across cultures," Annual Review of Public Health, vol. 34, pp. 119-138, 2013.

[21] O. P. Almeida, H. Alfonso, G. J. Hankey, and L. Flicker, "Depression, antidepressant use and mortality in later life: the Health In Men Study," PLoS One, vol. 5, no. 6, p. e11266, 2010.

[22] M. Luca, S. Bellia, M. Bellia, A. Luca, and C. Calandra, "Prevalence of depression and its relationship with work characteristics in a sample of public workers," Neuropsychiatric Disease and Treatment, vol. 10, pp. 519-525, 2014.

[23] H. O. Taylor, R. J. Taylor, A. W. Nguyen, and L. Chatters, "Social isolation, depression, and psychological distress among older adults," Journal of Aging and Health, vol. 30, no. 2, pp. 229-246, 2018.

[24] K. M. Han, M. S. Kim, A. Kim, J. W. Paik, J. Lee, and B. J. Ham, "Chronic medical conditions and metabolic syndrome as risk factors for incidence of major depressive disorder: a longitudinal study based on 4.7 million adults in South Korea," Journal of Affective Disorders, vol. 257, pp. 486-494, 2019.

[25] G. S. Alexopoulos, M. L. Bruce, D. Silbersweig, B. Kalayam, and E. Stern, "Vascular depression: a new view of late-onset depression," Dialogues in Clinical Neuroscience, vol. 1, no. 2, pp. 68-80, 1999.

[26] K. I. Salo, J. Scharfen, I. D. Wilden, R. I. Schubotz, and H. Holling, "Confining the concept of vascular depression to late-onset depression: a meta-analysis of MRI-defined hyperintensity burden in major depressive disorder and bipolar disorder," Frontiers in Psychology, vol. 10, 2019. 
[27] F. E. De Leeuw, J. C. de Groot, E. Achten et al., "Prevalence of cerebral white matter lesions in elderly people: a population based magnetic resonance imaging study. The Rotterdam Scan Study," Journal of Neurology, Neurosurgery, and Psychiatry, vol. 70, no. 1, pp. 2-3, 2012.

[28] J. C. Kovacic, P. Moreno, E. G. Nabel, V. Hachinski, and V. Fuster, "Cellular senescence, vascular disease, and aging. Part 2 of a 2-part review: clinical vascular disease in the elderly," Circulation, vol. 123, no. 17, pp. 1900-1910, 2011.

[29] M. E. Culang-Reinlieb, L. C. Johnert, A. M. Brickman, D. C. Steffens, E. Garcon, and J. R. Sneed, "MRI-defined vascular depression: a review of the construct," International Journal of Geriatric Psychiatry, vol. 26, no. 11, pp. 1101-1108, 2011.

[30] E. Teper and J. T. O'Brien, "Vascular factors and depression," International Journal of Geriatric Psychiatry, vol. 23, no. 10, pp. 993-1000, 2008.

[31] M. Virtanen, J. E. Ferrie, T. Akbaraly et al., "Metabolic syndrome and symptom resolution in depression: a 5-year follow-up of older adults," The Journal of Clinical Psychiatry, vol. 78, no. 1, pp. e1-e7, 2017.

[32] S. V. Bădescu, C. Tătaru, L. Kobylinska et al., "The association between diabetes mellitus and depression," Journal of Medicine and Life, vol. 9, no. 2, pp. 120-125, 2016.

[33] P. Bhatia and N. Singh, "Homocysteine excess: delineating the possible mechanism of neurotoxicity and depression," Fundamental \& Clinical Pharmacology, vol. 29, no. 6, pp. 522-528, 2015.

[34] S. Najjar, D. M. Pearlman, O. Devinsky, A. Najjar, and D. Zagzag, "Neurovascular unit dysfunction with blood-brain barrier hyperpermeability contributes to major depressive disorder: a review of clinical and experimental evidence," Journal of Neuroinflammation, vol. 10, no. 1, 2013.

[35] C. Betzen, R. White, C. M. Zehendner et al., "Oxidative stress upregulates the NMDA receptor on cerebrovascular endothelium," Free Radical Biology and Medicine, vol. 47, no. 8, pp. 1212-1220, 2009.

[36] R. G. Rempe, A. M. S. Hartz, and B. Bauer, "Matrix metalloproteinases in the brain and blood-brain barrier: versatile breakers and makers," Journal of Cerebral Blood Flow and Metabolism, vol. 36, no. 9, pp. 1481-1507, 2016.

[37] K. Bobińska, J. Szemraj, P. Czarny, and P. Gałecki, "Expression and activity of metalloproteinases in depression," Medical Science Monitor, vol. 22, pp. 1334-1341, 2016.

[38] H. Mizoguchi, K. Yamada, and T. Nabeshima, "Matrix metalloproteinases contribute to neuronal dysfunction in animal models of drug dependence, Alzheimer's disease, and epilepsy," Biochemistry Research International, vol. 2011, 10 pages, 2011.

[39] D. da Cunha Nascimento, R. de Cassia Marqueti Durigan, R. A. Tibana, J. L. Q. Durigan, J. W. Navalta, and J. Prestes, "The response of matrix metalloproteinase- 9 and -2 to exercise," Sports Medicine, vol. 45, no. 2, pp. 269-278, 2015.

[40] M. Guo, B. Cox, S. Mahale et al., "Pre-ischemic exercise reduces matrix metalloproteinase- 9 expression and ameliorates blood-brain barrier dysfunction in stroke," Neuroscience, vol. 151, no. 2, pp. 340-351, 2008.

[41] A. Schmidt, J. Pleiner, M. Bayerle-Eder et al., "Regular physical exercise improves endothelial function in heart transplant recipients," Clinical Transplantation, vol. 16, no. 2, pp. 137143, 2002.
[42] R. Hambrecht, V. Adams, S. Erbs et al., "Regular physical activity improves endothelial function in patients with coronary artery disease by increasing phosphorylation of endothelial nitric oxide synthase," Circulation, vol. 107, no. 25, pp. 3152-3158, 2003.

[43] C. D. Wiener, F. P. Moreira, L. V. Portela et al., "Interleukin-6 and interleukin-10 in mood disorders: a populationbased study," Psychiatry Research, vol. 273, pp. 685-689, 2019.

[44] A. Andréasson, L. Arborelius, C. Erlanson-Albertsson, and M. Lekander, "A putative role for cytokines in the impaired appetite in depression," Brain, Behavior, and Immunity, vol. 21, no. 2, pp. 147-152, 2007.

[45] A. Luca, M. Luca, and C. Calandra, "Eating disorders in latelife," Aging and Disease, vol. 6, no. 1, pp. 48-55, 2015.

[46] A. Luca, C. Calandra, and M. Luca, "Molecular bases of Alzheimer's disease and neurodegeneration: the role of neuroglia," Aging and Disease, vol. 9, no. 6, pp. 1134-1152, 2018.

[47] R. Yirmiya, N. Rimmerman, and R. Reshef, "Depression as a microglial disease," Trends in Neurosciences, vol. 38, no. 10, pp. 637-658, 2015.

[48] E. Pistorio, M. Luca, A. Luca, V. Messina, and C. Calandra, "Autonomic nervous system and lipid metabolism: findings in anxious-depressive spectrum and eating disorders," Lipids in Health and Disease, vol. 10, no. 1, p. 192, 2011.

[49] M. Kadoya and H. Koyama, "Sleep, autonomic nervous function and atherosclerosis," International Journal of Molecular Sciences, vol. 20, no. 4, p. 794, 2019.

[50] M. Luca, A. Luca, and C. Calandra, "Accelerated Aging in Major Depression: The Role of Nitro-Oxidative Stress," Oxidative Medicine and Cellular Longevity, vol. 2013, Article ID 230797, 6 pages, 2013.

[51] P. Sachdev, R. Kalaria, J. O'Brien et al., "Diagnostic criteria for vascular cognitive disorders: a VASCOG statement," Alzheimer Disease and Associated Disorders, vol. 28, no. 3, pp. 206218, 2014.

[52] F. J. Wolters and M. A. Ikram, "Epidemiology of vascular dementia," Arteriosclerosis, Thrombosis, and Vascular Biology, vol. 39, no. 8, pp. 1542-1549, 2019.

[53] S. T. Pendlebury, P. M. Rothwell, and Oxford Vascular Study, "Incidence and prevalence of dementia associated with transient ischaemic attack and stroke: analysis of the populationbased Oxford Vascular Study," Lancet Neurology, vol. 18, no. 3, pp. 248-258, 2019.

[54] J. T. O'Brien and A. Thomas, "Vascular dementia," Lancet, vol. 386, no. 10004, pp. 1698-1706, 2015.

[55] L. Pantoni, "Cerebral small vessel disease: from pathogenesis and clinical characteristics to therapeutic challenges," Lancet Neurology, vol. 9, no. 7, pp. 689-701, 2010.

[56] J. C. M. Zijlmans, S. E. Daniel, A. J. Hughes, T. Révész, and A. J. Lees, "Clinicopathological investigation of vascular parkinsonism, including clinical criteria for diagnosis," Movement Disorders, vol. 19, no. 6, pp. 630-640, 2004.

[57] G. Mostile, A. Nicoletti, C. E. Cicero et al., "Magnetic resonance parkinsonism index in progressive supranuclear palsy and vascular parkinsonism," Neurological Sciences, vol. 37, no. 4, pp. 591-595, 2016.

[58] B. C. Stephan, F. E. Matthews, B. Ma et al., "Alzheimer and vascular neuropathological changes associated with different cognitive states in a non-demented sample," Journal of Alzheimer's Disease, vol. 29, no. 2, pp. 309-318, 2012. 
[59] D. Andriuta, M. Roussel, M. Barbay, S. Despretz-Wannepain, O. Godefroy, and Godefroy and GRECogVASC study group, "Differentiating between Alzheimer's disease and vascular cognitive impairment: is the "memory versus executive function" contrast still relevant?," Journal of Alzheimer's Disease, vol. 63, no. 2, pp. 625-633, 2018.

[60] A. Khan, R. N. Kalaria, A. Corbett, and C. Ballard, "Update on vascular dementia," Journal of Geriatric Psychiatry and Neurology, vol. 29, no. 5, pp. 281-301, 2016.

[61] L. Park, J. Anrather, H. Girouard, P. Zhou, and C. Iadecola, "Nox2-derived reactive oxygen species mediate neurovascular dysregulation in the aging mouse brain," Journal of Cerebral Blood Flow and Metabolism, vol. 27, no. 12, pp. 1908-1918, 2007.

[62] N. S. Banko, C. S. McAlpine, D. E. Venegas-Pino et al., "Glycogen synthase kinase $3 \alpha$ deficiency attenuates atherosclerosis and hepatic steatosis in high fat diet-fed low density lipoprotein receptordeficient mice," The American Journal of Pathology, vol. 184, no. 12, pp. 3394-3404, 2014.

[63] A. Luca, C. Calandra, and M. Luca, "Gsk3 signalling and redox status in bipolar disorder: evidence from lithium efficacy," Oxidative Medicine and Cellular Longevity, vol. 2016, Article ID 3030547, 12 pages, 2016.

[64] P. Toth, S. Tarantini, A. Csiszar, and Z. Ungvari, "Functional vascular contributions to cognitive impairment and dementia: mechanisms and consequences of cerebral autoregulatory dysfunction, endothelial impairment, and neurovascular uncoupling in aging," American Journal of Physiology. Heart and Circulatory Physiology, vol. 312, no. 1, pp. H1-H20, 2017.

[65] R. S. Beard Jr., J. J. Reynolds, and S. E. Bearden, "Hyperhomocysteinemia increases permeability of the blood-brain barrier by NMDA receptor-dependent regulation of adherens and tight junctions," Blood, vol. 118, no. 7, pp. 2007-2014, 2011.

[66] M. D. Sweeney, A. Montagne, A. P. Sagare et al., "Vascular dysfunction-the disregarded partner of Alzheimer's disease," Alzheimers Dement, vol. 15, no. 1, pp. 158-167, 2019.

[67] M. Luca, A. Luca, and C. Calandra, "The role of oxidative damage in the pathogenesis and progression of Alzheimer's disease and vascular dementia," Oxidative Medicine and Cellular Longevity, vol. 2015, Article ID 504678, 8 pages, 2015.

[68] Y. Netz, M. J. Wu, B. J. Becker, and G. Tenenbaum, "Physical activity and psychological well-being in advanced age: a meta-analysis of intervention studies," Psychology and Aging, vol. 20, no. 2, pp. 272-284, 2005.

[69] J. A. Blumenthal, M. A. Babyak, K. A. Moore et al., "Effects of exercise training on older patients with major depression," Archives of Internal Medicine, vol. 159, no. 19, pp. 23492356, 1999.

[70] A. S. Mather, C. Rodriguez, M. F. Guthrie, A. M. McHarg, I. C. Reid, and M. E. T. McMurdo, "Effects of exercise on depressive symptoms in older adults with poorly responsive depressive disorder," The British Journal of Psychiatry, vol. 180, no. 5, pp. 411-415, 2002.

[71] C. Bridle, K. Spanjers, S. Patel, N. M. Atherton, and S. E. Lamb, "Effect of exercise on depression severity in older people: systematic review and meta-analysis of randomised controlled trials," The British Journal of Psychiatry, vol. 201, no. 3, pp. 180-185, 2012.

[72] B. S. Diniz, M. A. Butters, S. M. Albert, M. A. Dew, and C. F. Reynolds, "Late-life depression and risk of vascular dementia and Alzheimer's disease: systematic review and meta-analysis of community-based cohort studies," The British Journal of Psychiatry, vol. 202, no. 5, pp. 329-335, 2013.

[73] D. E. Barnes, K. Yaffe, W. A. Satariano, and I. B. Tager, “A longitudinal study of cardiorespiratory fitness and cognitive function in healthy older adults," Journal of the American Geriatrics Society, vol. 51, no. 4, pp. 459-465, 2003.

[74] A. L. Smiley-Oyen, K. A. Lowry, S. J. Francois, M. L. Kohut, and P. Ekkekakis, "Exercise, fitness, and neurocognitive function in older adults: the "selective improvement" and "cardiovascular fitness" hypotheses," Annals of Behavioral Medicine, vol. 36, no. 3, pp. 280-291, 2008.

[75] A. M. Stranahan, B. Martin, and S. Maudsley, "Anti-inflammatory effects of physical activity in relationship to improved cognitive status in humans and mouse models of Alzheimer's disease," Current Alzheimer Research, vol. 9, no. 1, pp. 86-92, 2012.

[76] L. J. Trigiani and E. Hamel, “An endothelial link between the benefits of physical exercise in dementia," Journal of Cerebral Blood Flow and Metabolism, vol. 37, no. 8, pp. 2649-2664, 2017.

[77] V. A. Holthoff, K. Marschner, M. Scharf et al., "Effects of physical activity training in patients with Alzheimer's dementia: results of a pilot RCT study," PLoS One, vol. 10, no. 4, p. e0121478, 2015.

[78] T. Liu-Ambrose, J. R. Best, J. C. Davis et al., "Aerobic exercise and vascular cognitive impairment: a randomized controlled trial," Neurology, vol. 87, no. 20, pp. 2082-2090, 2016.

[79] T. Liu-Ambrose, J. J. Eng, L. A. Boyd et al., "Promotion of the mind through exercise (PROMoTE): a proof-of-concept randomized controlled trial of aerobic exercise training in older adults with vascular cognitive impairment," BMC neurology, vol. 10, no. 1, 2010.

[80] M. Gomes, D. Figueiredo, L. Teixeira et al., "Physical inactivity among older adults across Europe based on the SHARE database," Age and Ageing, vol. 46, no. 1, pp. 71-77, 2016. 


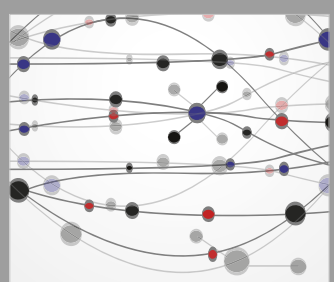

The Scientific World Journal
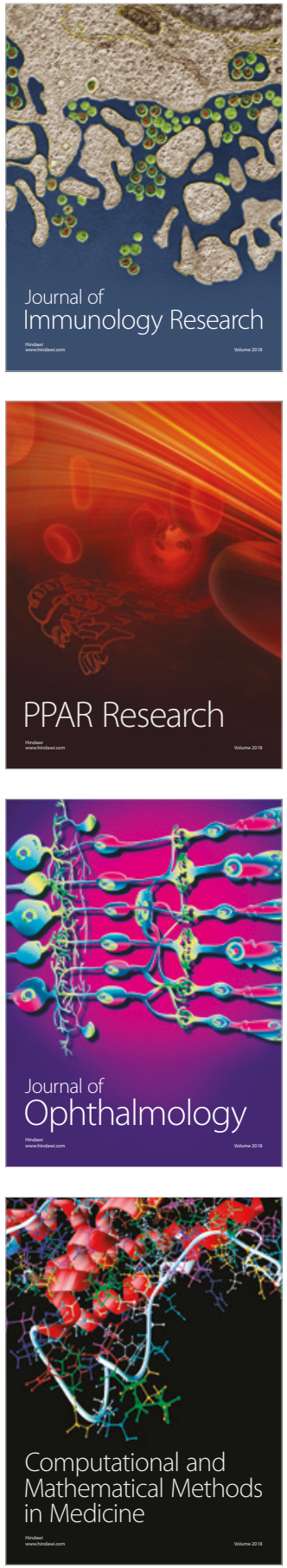

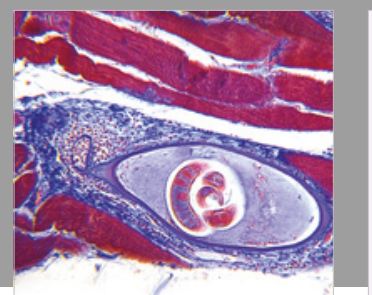

Gastroenterology Research and Practice

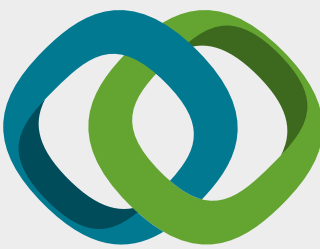

\section{Hindawi}

Submit your manuscripts at

www.hindawi.com
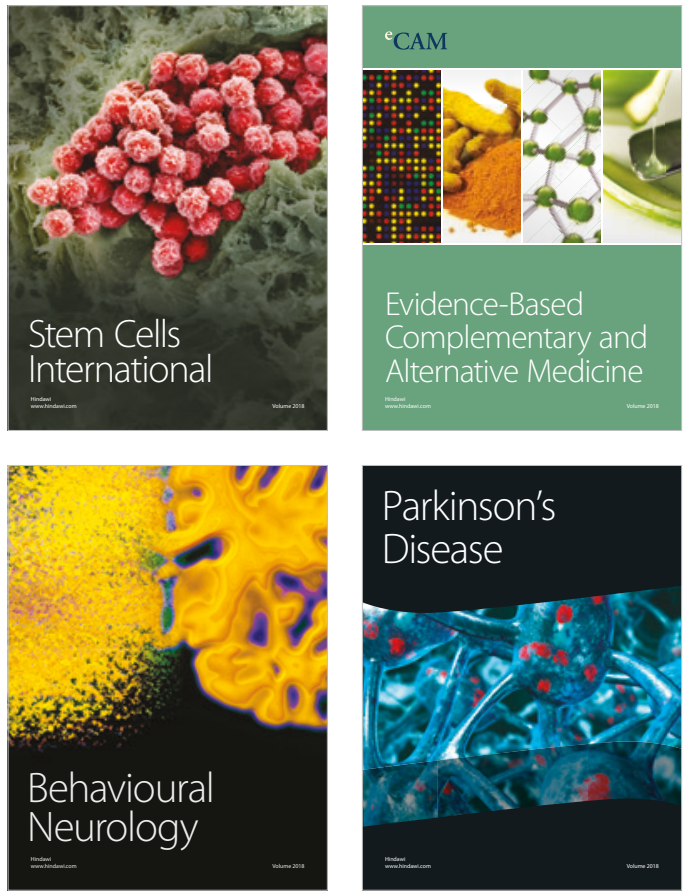

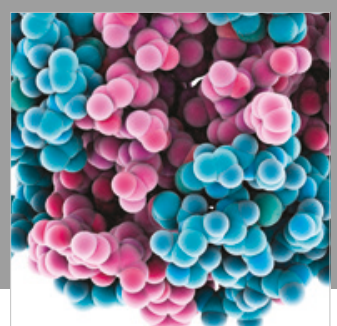

ournal of

Diabetes Research

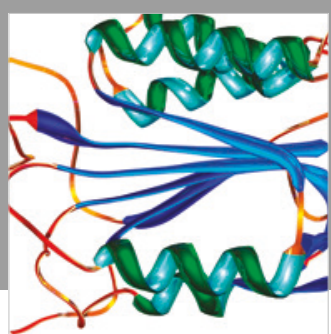

Disease Markers
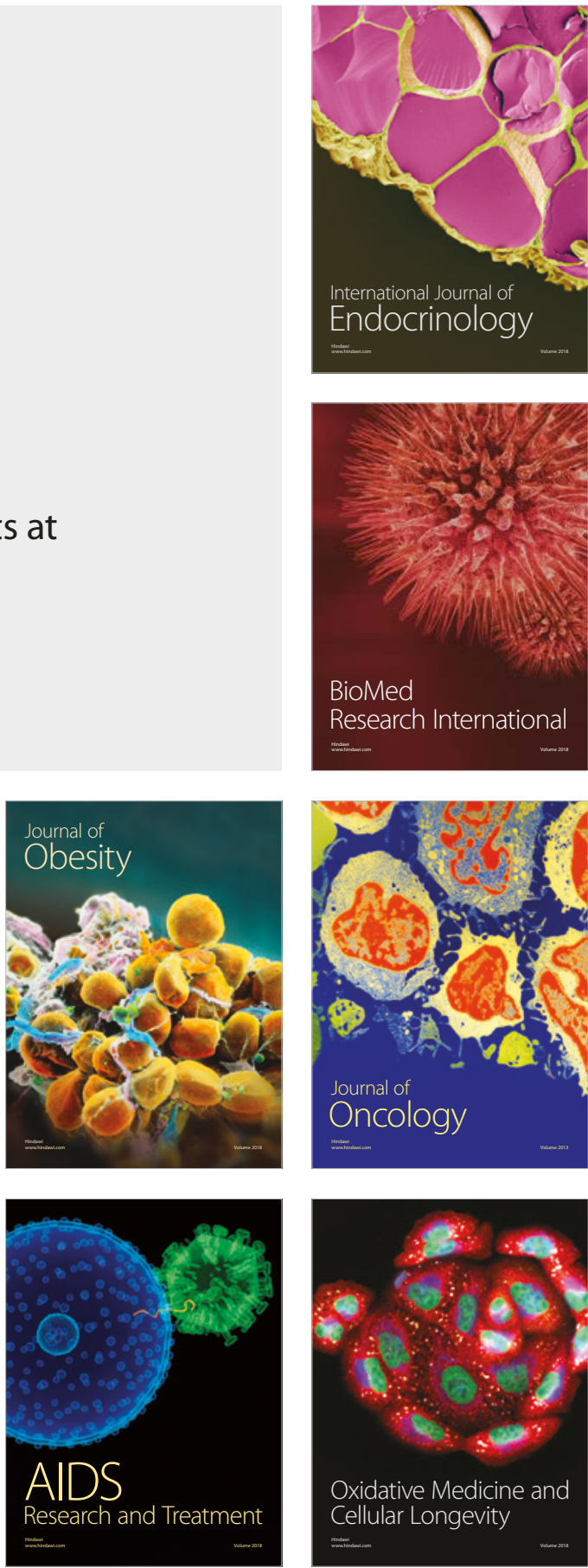